\title{
LA LEGÍTIMA Y LA CAUSA DE DESHEREDAMIENTO POR ABANDONO FAMILIAR. ¿HACIA UNA MAYOR LIBERTAD DE TESTAR?*
}

\author{
THE RESERVED PORTION AND THE DISINHERITANCE CAUSE \\ FOR FAMILY ABANDONMENT. TOWARDS GREATER FREEDOM \\ TO MAKE WILLS?
}

\section{Gerard RiNCÓN ANDREU**}

RESUMEN: En derecho de sucesiones, el testador no goza de libertad absoluta para disponer sobre su patrimonio, configurándose un sistema de derechos forzosos presidido por la legítima. Tanto en derecho positivo catalán, español como colombiano hay una arraigada tradición socio-jurídica que sustenta la legítima a partir del principio de solidaridad interfamiliar, lo cual dificulta aplicar teorías radicales como las de supresión de dicha institución con carácter de orden público o su configuración bajo estrictos parámetros de necesidad del legitimario. Con todo, la previsión de nuevas causales de indignidad y desheredamiento como el abandono familiar, así como la reducción de la cuota de legítima en Colombia avecinan una mayor libertad de testar como tendencia lógica en la sociedad actual.

Palabras clave: derecho de sucesiones, herencia, legítima, testamento, desheredamiento, abandono familiar.
ABSTRACT: In inheritance law, the testator does not enjoy absolute freedom to dispose of his assets, configuring a system of mandatory law presided by the reserved portion. Both in Catalan, Spanish and Colombian positive law, there is a deep-rooted socio-legal tradition that supports the reserved portion based on the principle of interfamily solidarity, which complicates the application of radical theories such as the suppression of said public order institution or its configuration under strict need parameters of the heir-at-law. However, the legal provisions of new causes of indignity and disinheritance such as family abandonment, as well as the reduction of the reserved portion in Colombia glimpse a greater freedom to make wills as a logical trend in today's society.

Keyzerds: inheritance law, inheritance, reserved portion, will, disinheritance, family abandonment.

* Registrado el 23 de enero de 2020; aprobado el 27 de enero de 2021.

** ORCID: 0000-0001-8201-1683. Profesor de Derecho civil, Universidad Santiago de Cali; profesor colaborador Grado de Derecho, Universitat Oberta de Catalunya. Abogado

Boletín Mexicano de Derecho Comparado, nueva serie, año LIV, núm. 160, enero-abril de 2021, pp. 361-385. 
SUMARIO: I. Introducción. II. En pro de una legítima corta. III. Ausencia de relación familiar como causa de desheredamiento. IV. ¿Hacia una mayor libertad de testar? V. Conclusiones. VI. Bibliografia.

\section{INTRODUGGIÓN}

El avance y variabilidad del derecho es incesante, apareciendo nuevas realidades, aplicaciones e interpretaciones que nos obligan a un constante estudio y actualización tanto en el ámbito jurisprudencial como dogmático.

Las nuevas tendencias en derecho privado nos han conducido, en los últimos años, hacia la materialización de novedades jurídicas importantes. En este sentido, el derecho de sucesiones no es una excepción, avecinándose una propensión global hacia una mayor libertad para testar. En primer lugar, esto deviene de una sólida teoría conducente a la necesidad de reconfigurar la institución de la legítima, a fin de que sea coherente con la nueva realidad y necesidad social. En segundo lugar, porque la introducción de una nueva causal para el desheredamiento, como es el abandono o falta de relación familiar, ya viene otorgando, de facto, una mayor autonomía de la libertad para el testador.

En suma, el objetivo de esta investigación es argüir una clara apuesta por el modelo de legítima corta regulado en el Código Civil de Cataluña (en adelante, CGCat), no siendo óbice para cuestionar la propia naturaleza y utilidad actual de la institución de la legítima, planteándose luces y sombras ante una posible supresión o cambio de configuración de ésta. Además, también cabrá destacar el carácter pionero del derecho civil catalán en la previsión de la causal de desheredamiento por abandono familiar; conduciéndonos, todo ello, a formular un alegato final que aboga por una más amplia libertad testamentaria.

De este modo, la metodología utilizada para el desarrollo de este estudio es la propia de la investigación jurídica de carácter hermenéutico, analizándose esencialmente - de forma sistematizada - la normativa y doctrina en el sí de tres ordenamientos jurídicos: el catalán, el español y el colombiano. Por tanto, estas breves reflexiones que se pretenden exponer están basadas en un estudio de micro-comparación en derecho

del Ilustre Colegio de Abogados de Barcelona; investigador del Grupo de Investigación GICPODERI. Correo electrónico: gerardrincon@usc.edu.co.

Esta obra está bajo una Licencia Creative Commons

Atribución-NoComercial-SinDerivar 4.0 Internacional, IIJ-UNAM.

Boletín Mexicano de Derecho Comparado, núm. 160, enero-abril de 2021, pp. 361-385. 
privado, más concretamente en derecho sucesorio. A mayor concreción, la primera parte del texto es de carácter normativista, partiendo de la comparación de disposiciones normativas en materia sucesoria de los códigos civiles de los tres ordenamientos estudiados. Sin embargo, en su recta final se asume una metodología argumentativista y no meramente descriptiva, pues se analizará la idoneidad de la misma legislación, proponiéndose un deber ser de la vigencia interpretativa de la legítima.

\section{EN PRO DE UNA LEGÍTIMA CORTA}

La sucesión tiene una gran relevancia social y económica, ya que da sentido a la acumulación de patrimonio y su posible traspaso garantiza un sistema económico fundamentado en la propiedad privada de bienes perdurables. La transmisión de titularidades, derechos y obligaciones mediante la sucesión es una decisión básica del ordenamiento jurídico, la cual en España, incluso goza de reconocimiento constitucional explícito, al prever la Constitución Española (art. 33) que "se reconoce el derecho a la propiedad privada y a la herencia". 1

Además, el derecho a la herencia tiene una innegable función social en estrecha correlación con la protección de los intereses familiares, con el reconocimiento de derechos legitimarios a los hijos y, otorgando también, con carácter defectivo, protección al cónyuge o a la pareja estable. ${ }^{2}$

Si bien el derecho a la herencia parte fundamentalmente del principio básico de "libertad" para testar, esta facultad del causante no es plena,

1 Como vemos, el reconocimiento constitucional de la herencia se vincula con el derecho a la propiedad privada. En Colombia, también se concede reconocimiento constitucional al derecho a la herencia, a tenor del contenido del artículo 58 de su Constitución Política: "Se garantizan la propiedad privada y los demás derechos adquiridos con arreglo a las leyes civiles, los cuales no pueden ser desconocidos ni vulnerados por leyes posteriores".

2 Ya sea, en Cataluña, con el derecho a la cuarta vidual (CGCat, art. 452-1) o, en Colombia, por medio de la porción conyugal (CGco, art. 1230) como mecanismo de protección al cónyuge o conviviente sobreviviente que carece de lo necesario para su congrua subsistencia. 
puesto que se encuentra restringida, en parte, por un sistema de derechos forzosos en el cual destaca esencialmente la legítima. ${ }^{3}$

Antes de desgranar los principales caracteres de la institución de legítima en la legislación comparada, es preciso hacer una breve referencia a sus orígenes, ya que no es ni mucho menos una figura que apareciera en España o Colombia en sus respectivos códigos civiles de 1889 y 1887. En efecto, ya en el derecho romano, a partir del siglo II se empieza a entender que los hijos y parientes cercanos no pueden apartarse de la sucesión. (Alejandro Platero, 2017, p. 289)

Por reproducción literal del Código Civil colombiano (en adelante, CCco, art. 1239) la "legítima es aquella cuota de los bienes de un difunto que la ley asigna a ciertas personas llamadas legitimarios". Prosigue este precepto disponiendo, in fine, que "los legitimarios son, por consiguiente, herederos". Precisamente, aquí radica el quid de la cuestión, vislumbrándose una diferencia capital entre derecho sucesorio colombiano y catalán que acto seguido intentaré esbozar.

En Cataluña los legitimarios no coinciden necesariamente con los herederos, hay una separación rigurosa entre ambas figuras. De hecho, cabe destacar como principio particular del derecho sucesorio catalán la necesidad de la "institución de heredero"4 - como sucesor a título universalpara que un testamento sea válido (CCCat, art. 423-1). Es más, como regla general, un testamento que no contenga la institución de heredero devendrá nulo (CGCat, art. 422-1.3), si bien este principio admite dos excepciones: el nombramiento de "albacea universal", de forma que toda la herencia se reparte en legados o bien es líquida y se destina a la finali-

3 Como recuerda el profesor Jesús Delgado (2006, pp. 124 y 125), "hay que tener en cuenta que las previsiones legislativas sobre derechos sucesorios forzosos cumplen la finalidad de subvenir a las desviaciones no deseadas o no compartidas socialmente del testador medio". No obstante, "habitualmente los testadores se guían por sus vínculos familiares y afectivos y favorecen a sus allegados, y sólo de manera poco frecuente el causante favorece a extraños con los que carece de todo vínculo desamparando a su propia familia".

4 El libro IV del CGCat mantiene este principio tradicional y prevé reglas de interpretación y de integración de la voluntad del testador cuando la institución del heredero no es suficientemente clara. (Albert Lamarca, 2009b, p. 57)

5 Este artículo 423-1 del CCCat, en su primer apartado, dispone que "El testamento debe contener necesariamente institución de heredero". Por su parte, el artículo 421-2 expresa que "en testamento, el causante ordena su sucesión mediante la institución de uno o más herederos" pudiendo, lógicamente, establecer también legados y otras disposiciones.

Esta obra está bajo una Licencia Creative Commons

Atribución-NoComercial-SinDerivar 4.0 Internacional, IIJ-UNAM.

Boletín Mexicano de Derecho Comparado, núm. 160, enero-abril de 2021, pp. 361-385. 
dades previstas por el testador; o el hecho de que el testador esté sometido al específico derecho de Tortosa, ámbito en el cual también se admite distribuir toda la herencia mediante legados.

\section{De los legitimarios}

Sin necesidad de mayor detenimiento en cuanto a la definición de la legítima, y a sabiendas de la configuración de la "institución de heredero" como característica propia del derecho catalán, procede determinar los legitimarios y la distribución de sus cuotas en los tres ordenamientos jurídicos objeto de estudio, a fin de apreciar un mínimo común denominador y, a la vez, sus rasgos diferenciales.

Por un lado, en Cataluña el círculo de legitimarios solamente incluye a los parientes en línea directa del causante, sin límites en la descendiente y restringido a los padres o progenitores en la línea ascendiente. ${ }^{6}$ El cónyuge o conviviente, pues, no puede ser considerado como legitimario, aunque sí tiene derecho a la cuarta viudal como atribución legal (Albert Lamarca, 2009 a, p. 264). Asimismo, a tenor del redactado del CCCat (art. 451-3.1), los legitimarios son todos los hijos del causante por partes iguales. La previsión de legítima para los progenitores será única y exclusivamente en el supuesto de que el causante no tenga descendientes que le hubieran sobrevivido, siendo en este caso legitimarios los progenitores por mitad. ${ }^{7}$

Por otro lado, en España, según regulación del Código Civil español (en adelante, CCesp, art. 807), son legitimarios los hijos y descendientes; a falta de los anteriores, los padres y ascendientes; en tercer lugar, "el viudo o viuda en la forma y medida que establece este Código". ${ }^{8}$

\footnotetext{
6 Véase CCCat (arts. 451-3 y 451-4).

7 Es más, estos no tienen derecho a legítima si el causante tiene descendientes pero han sido desheredados justamente o declarados indignos (CCGat, art. 451-4.1).

8 En este sentido, si el cónyuge del difunto concurre a la herencia con descendientes, tendrá derecho al usufructo del tercio de mejora (CGesp, art. 834); si concurre con ascendientes tendrá derecho al usufructo de la mitad de la herencia (CCesp, art. 837), y no existiendo descendientes ni ascendientes, el cónyuge sobreviviente tendrá derecho al usufructo de los dos tercios de la herencia (CCesp, art. 838).
}

Esta obra está bajo una Licencia Creative Commons Atribución-NoComercial-SinDerivar 4.0 Internacional, IIJ-UNAM. Boletín Mexicano de Derecho Comparado, núm. 160, enero-abril de 2021, pp. 361-385. 
Finalmente, en lo que a Colombia se refiere, el CGco (art. 1240) determina el rango de los llamados a ser legitimarios, disponiendo primeramente a los descendientes personalmente o representados - con independencia de que los hijos sean matrimoniales, extramatrimoniales o adoptivos - . Acto seguido, serán legitimarios los ascendientes. ${ }^{9}$

Así pues, vale la pena enfatizar que tanto en España como en Colombia se yuxtapone la institución de heredero con la de legitimario, derivando este en heredero forzoso, ${ }^{10}$ lo cual viene a suponer una anomalía y una intolerable coerción a la libertad de testar.

En contraposición al modelo anterior, se destaca la singularidad del CCCat, en el cual los herederos no tienen que ser, forzosamente, los hijos o parientes del causante, pudiéndose instituir como heredero cualquier otra persona, por lo que se disocia la institución de heredero de la de legitimario. Por esa razón, aunque en Cataluña cabe calificar la legítima como un derecho de crédito, más congruente con el principio de libertad testamentaria, ${ }^{11}$ en general

la legítima admite una doble configuración, como herencia forzosa, en el sentido que los legitimarios adquieren un derecho en bienes de la herencia, o como derecho de crédito a un valor de los bienes de la herencia que debe ejercitarse frente a los herederos o los representantes de la herencia y se percibe en metálico. (Antoni Vaquer, 2007, p. 7)

En definitiva, en Cataluña, sólo en el supuesto de sucesión ab intestato operará un orden sucesoral predeterminado que favorecerá que los

9 El CGcol (art. 1240) ha sido modificado por el artículo 3o. de la Ley 1934 de 2018, por medio de la cual se reforma y adiciona el Código Civil. Anteriormente, el precepto contenía una prelación de legitimarios de forma que - tras los descendientes - primaba, en primer lugar, los ascendientes, y tras ellos, los padres adoptantes y los padres de sangre del hijo adoptivo de forma simple.

10 Esta yuxtaposición heredero-legitimario se desprende de forma nítida del CGco (art. 1239, in fine), el cual recoge que "los legitimarios son, por consiguiente, herederos". También del CCesp, cuando en su capítulo segundo, sección quinta "De las legítimas", se denomina a los legitimaros propiamente como "herederos forzosos". (CCesp, art. 807)

11 "La apuesta por una legítima de naturaleza crediticia se corresponde mejor con una más amplia libertad de testar que si se otorga un derecho sobre los bienes hereditarios, pues esto supone que parte de la herencia siga en manos de la familia del causante con independencia de que esa fuera la voluntad del causante o no". (Antoni Vaquer, 2007, p. 7)

Esta obra está bajo una Licencia Creative Commons

Atribución-NoComercial-SinDerivar 4.0 Internacional, IIJ-UNAM.

Boletín Mexicano de Derecho Comparado, núm. 160, enero-abril de 2021, pp. 361-385. 
familiares del causante devengan herederos, ${ }^{12}$ puesto que, en la sucesión testada será la figura de la legítima la garante de la solidaridad intergeneracional entre los miembros de la familia.

\section{De la cuota legitimaria y su disparidad}

En cuanto a la cuota a repartir para los legitimarios, en Colombia la legítima se encuentra regulada en el CGcol (arts. 1239-1264). Hasta ahora se entendía dividido el caudal hereditario en dos mitades: la primera venía a ser la legítima rigurosa, reservada para los legitimarios, mientras que la otra mitad, en caso de inexistencia de descendientes, era de libre disposición, siendo apenas una cuarta parte la libre asignación cuando existían los descendientes. En tal caso, se proponía que no se hiciese la división en dos mitades sino en cuatro partes, dos de las cuales vendrían a ser las legítimas, una cuarta sería para mejorar a descendientes del causante y la otra vendría a ser de libre disposición. (Ramiro Rodríguez, 2012, p. 162)

Recientemente, encomiable ha sido la labor del senador de la República de Colombia Rodrigo Lara Restrepo, quien presentó una iniciativa de ley para ampliar la libertad sucesoral. Finalmente, este proyecto ha obtenido luz verde por el Congreso y se ha aprobado como Ley 1934 de 2018, el 2 de agosto, por medio de la cual se reforma y adiciona el CGcol, modificando y derogando múltiples artículos en materia legitimaria. ${ }^{13}$

En resumen, con la mencionada reforma del CGcol se elimina la cuarta de mejoras ${ }^{14}$ y la herencia se divide en dos grandes partes: la mitad para los legitimarios (legítima rigurosa) y la mitad de libre disposición. ${ }^{15}$ En cuanto a las legítimas efectivas, acrece a las legítimas rigurosas

12 Tamayo (2008, p. 93) afirma que la noción de orden sucesoral hace referencia a un "grupo de personas que tiene prelación sobre otro grupo para recoger la herencia de un causante".

13 Las disposiciones de esta nueva normativa están en vigor a partir del 1o. de enero de 2019, no siendo aplicables a los testamentos que hayan sido depositados en notaría antes de su vigencia.

14 Con la Ley 1934 de 2018 se derogan los artículos 1243, 1252, 1253, 1259 y 1262 del CGcol, relacionados con la cuarta de mejoras.

15 Véase la nueva redacción del CGcol (art. 1242), por el cual, en todo caso la cuota legitimaria será de la mitad de los bienes, tras las deducciones ex art. 1016 y las agregaciones que indican los arts. 1243 a 1245. Prosigue disponiendo que los bienes "se dividen 
"toda aquella porción de los bienes de que el testador ha podido disponer con absoluta libertad, y no ha dispuesto, y si lo ha hecho ha quedado sin efecto la disposición". (CGcol, art. 1249)

A modo de crítica, hay que decir que la agudeza del legislador en la promulgación de la Ley 1934 de 2018 brilla por su ausencia. Sorprende y es particularmente desafortunada la mención a la "cuarta de mejoras" en el CGcol (arts. 1242, 1254, 1261 y 1264) a pesar de ser una figura eliminada tras la mencionada reforma, lo cual no generará sino confusiones. Del mismo modo, desacertada es la redacción de la nueva Ley (art. 21), el cual dispone que "cuando vaya a disponerse testamentariamente de predios rurales de extensión inferior a cuatro (4) Unidades Agrícolas Familiares (UAF), no será aplicable el régimen de las legítimas". El alcance de este precepto no es diáfano, por no quedar claro si este tipo de predios rurales son de libre disposición, o bien si en presencia de esta clase de bienes es la totalidad de la herencia la que deviene de libre disposición. En consecuencia, vaticino que la interpretación no será pacífica y se derivaran debates interpretativos de gran calado jurídico.

Por su parte, en España opera un sistema de legítima de 2/3 en favor de los hijos: un tercio estricto - que se puede grabar con sustitución fideicomisaria en favor de un hijo incapacitado - ${ }^{16}$ y el otro tercio de mejora entre los legitimarios cuando son hijos o descendientes (CGesp, art. 808). Por tanto, solamente la tercera parte restante será de libre disposición. Cuando los legitimarios sean los padres o ascendientes constituirá la legítima "la mitad del haber hereditario de los hijos y descendientes, salvo el caso en que concurrieren con el cónyuge viudo del descendiente causante, en cuyo supuesto será de una tercera parte de la herencia” (CCesp, art. 809). En resumen, en España estas cuotas legitimarias "fluctúan, tras la realización de las pertinentes operaciones de cálculo de relictum y donatum, entre un cuarto y las cuatro quintas partes (del valor) de la herencia”. (Antoni Vaquer, 2007, p. 15)

De lo contrario, en Cataluña la legítima confiere a los legitimarios el derecho a percibir una cuarta parte del patrimonio hereditario (relicto,

por cabezas o estirpes entre los respectivos legitimarios, según las reglas de la sucesión intestada; lo que cupiere a cada uno de esta división es su legítima rigurosa".

16 Según el actual párrafo 3o. del art. 808 del CCesp, introducido por la Ley 41/2003, del 18 de noviembre, de protección patrimonial de las personas con discapacidad. 
líquido; descontando las deudas). Así, la libertad de disposición alcanza el $75 \%$, ya que solamente un 25\% está predeterminado por ley de forma forzosa en favor de los legitimarios (CCCat, art. 451-5). En consecuencia, el derecho catalán confiere mayor margen de lo que se viene denominando "libertad para testar", como reflejo de la libertad civil (CCCat, art. 111-6) o autonomía privada (CCesp, art. 1255).

Con todo, la evolución histórica de la legítima es la de su progresivo debilitamiento para dejar mayor libertad de disposición al causante y para evitar la fragmentación del patrimonio. Además, como se verá, el debate en la actualidad incluso va más allá, existiendo posiciones doctrinales, como las de Josep Ferrer (2008), que plantean la supresión de la legítima o su reforma para convertirla en un derecho que responda mejor a situaciones de necesidad. ${ }^{17}$ Es decir, lo que plantean estos autores es que los legitimarios tengan derecho a una cuota fija del caudal relicto, pero únicamente si estos se encuentran en la coyuntura de necesidad. En este caso, operaría la legítima en supuestos como los de legitimarios discapacitados o incapaces para trabajar, descendientes menores de edad, o en cumplimiento de una función similar al derecho de alimentos.

En suma, en los tres ordenamientos estudiados, en mayor o menor medida, la legítima se configura como una categórica limitación a la libertad testamentaria, suponiendo una injerencia del Estado en la esfera decisional de los ciudadanos. En España y Colombia porque los legitimarios se constituyen como herederos forzosos ${ }^{18}$ y, en Cataluña, por interpretarse la legítima como una sucesión forzosa. Tan forzosa es que existe en toda sucesión — testada e intestada-, está plenamente protegida (preterición) y sólo puede ser privada por justa causa de desheredamiento, sin que el testador la pueda prohibir o eliminar a su libre albedrío.

17 Se destaca que Josep María Puig (1984, p. 211 ) ya viene desde lejos abogando por su evanescencia, proclamando que "en Cataluña, a pesar de ser más bien corta, la legítima sigue su lento camino hacia la desaparición”.

18 Alejandro Platero (2017, p. 289), recuerda que ni esta denominación está exenta de polémica, ya que autores autorizados como Lacruz Berdejo, Acedo Penco o Román García, matizan que no es correcto llamar herederos forzosos a los legitimarios, dado que la legítima puede ser satisfecha en vida del causante por medio de donación o legado, sin que exista herencia alguna. 


\section{AUSENCIA DE RELACIÓN FAMILIAR COMO CAUSA DE DESHEREDAMIENTO}

La desheredación se define como aquel acto por el que el causante despoja al legitimario del caudal hereditario inmanente a la legítima. ${ }^{19}$

La desheredación se define como una sanción civil privada que debe hacer valer el causante si concurre una causa legal. Este estrecho margen para la libertad del causante implica que no caben otras vías indirectas para privar a los legitimarios de su derecho. (Paloma de Barrón, 2016, p. 11)

Pero, sin duda, este mecanismo de la desheredación presenta un amplio margen de discrecionalidad al causante, debiéndose prever obligatoriamente como cláusula testamentaria, la cual dependerá de su voluntad (María Elena Cobas y Christian de Joz, 2017, pp. 43 y 44).

Se desprende del CCesp (art. 849) que la desheredación sólo podrá hacerse en testamento. También el CGcol comparte esta versión, añadiendo (art. 1267) que no valdrá ninguna de las causas de desheredamiento si no se expresa en el testamento específicamente, "y si además no se hubiere probado judicialmente en vida del testador; o las personas a quienes interesare el desheredamiento no lo probaren después de su muerte". No obstante, el CGCat prevé dos instrumentos sucesorios, distintos al testamento que también habilitan a la desheredación: el codicilo y el pacto sucesorio (CCGat, art. 451-18.1).

Paloma de Barrón (2016) expone con precisión que la "cláusula de desheredación debe designar nominalmente al desheredado o, por lo menos, designarlo de forma individual e inequívoca, porque la naturaleza formal del desheredamiento impide que sea un acto genérico" (p. 12). Además, como antedicho, "tiene que expresarse la causa legal de desheredación, es decir, encajar la situación personal que se está viviendo en alguno de los preceptos legales que describen las causas de desheredación”. (p. 12) ${ }^{20}$

19 Ccesp (arts. 848 y ss), CGCat (art. 451-17.1). Y a diferencia de los otros dos ordenamientos comentados, el art. 1265 CGcol concreta que el desheredamiento podrá conllevar la privación "del todo o parte" de la legítima.

20 CGesp (art. 849), CGCat (V art. 451-17), CGco (art. 1266).

Esta obra está bajo una Licencia Creative Commons

Atribución-NoComercial-SinDerivar 4.0 Internacional, IIJ-UNAM.

Boletín Mexicano de Derecho Comparado, núm. 160, enero-abril de 2021, pp. 361-385. 
En Cataluña y España los efectos de la desheredación serán los mismos: si el legitimario desheredado es único, se extingue la legítima, no dando lugar a acrecimiento si hay otros legitimarios. Si el desheredado tuviese descendientes, estos devienen legitimarios por derecho de representación. ${ }^{21}$ Sin embargo, a diferencia de los dos ordenamientos mencionados, en Colombia sí habrá derecho de acrecimiento en caso de desheredamiento; ${ }^{22}$ no damnificando el desheredamiento, por regla general, los alimentos necesarios, exceptuando los casos de injuria atroz (CCcol, art. 1268).

El CGcol (art. 1268) expresa que "los efectos del desheredamiento, si el desheredador no los limitare expresamente, se extienden no sólo a las legítimas (...)". Mientras que, del CCCat (art. 451-17.1) se desprende que "el causante puede privar a los legitimarios de su derecho de legítima si en la sucesión concurre alguna causa de desheredación". En consecuencia, el redactado del precepto catalán nos podría llevar a pensar en la antinomia de que el causante solo puede privar, por vía del desheredamiento, de la legítima, y no propiamente de la herencia. No obstante, existiendo en Cataluña la libertad de erigir un heredero distinto a los familiares legitimarios, ¿alguien puede pensar que, por ejemplo, un testador quiera impedir la percepción de la legítima al hijo vía desheredación, pero simultáneamente lo instituya como heredero en su testamento?

Acometiendo ya la causal concreta de ausencia de relación familiar, en Cataluña, el CGCat (art. 451-17.1) establece que "se puede desheredar a los legitimarios por la ausencia manifiesta y continuada de relación familiar entre el causante y el legitimario, si es por una causa exclusivamente imputable al legitimario". En este sentido, "el legislador catalán se sitúa con esta postura en un término medio, entre los conceptos de libertad de testar, sucesión y protección de la familia; además de ir en consonancia con el resto de los derechos en el ámbito internacional que también optan por seguir esta corriente doctrinal". (María Elena Cobas y Christian de Joz, 2017, p. 22)

La adición de esta nueva causa se incorporó con la entrada en vigor el 1o. de enero de 2009 del libro cuarto del CCCat, relativo a las sucesio-

21 CCesp (art. 929), CCCat (art. 451-3.2), CGco (art. 1043).

22 Véase CCCat (art. 451-25.3). En cambio el CCcol (art. 1248) dispone que si un legitimario es desheredado y no tiene descendencia con derecho de representarle "dicho todo o parte se agregará a la mitad de legítimas, y contribuirá a formar las legítimas rigurosas de los otros, y la porción conyugal en el caso del artículo 1236, inciso 2". 
nes. ${ }^{23}$ Igualmente, el legislador catalán hizo un inciso significativo en el apartado VI del preámbulo del citado Libro, apreciando que este precepto podía ser "fuente de litigios por la dificultad probatoria de su supuesto de hecho", así como "conducir al juzgador a tener que hacer suposiciones sobre el origen de desavenencias familiares". Sin embargo, prosigue justificando tal previsión declarando que "se ha contrapesado este coste elevado de aplicación de la norma con el valor que tiene como reflejo del fundamento familiar de la institución y el sentido elemental de justicia que es subyacente".

En cambio, en derecho común español, la posibilidad de desheredar por falta de relación entre legitimario y ascendente todavía pasa en la actualidad por una interpretación extensiva del maltrato de obra que recoge como causa de desheredación el artículo 853.2 CCesp. (Hilario Mondragón, 2018, p. 17)

En este sentido, el Tribunal Supremo, viendo la inacción del legislador español y las escasas expectativas de que hubiera una reforma en materia de desheredación, decidió entrar en juego con una virtuosa labor hermenéutica, forzando la interpretación del "maltrato de obra" y el "maltrato psicológico" para amparar al causante ante supuestos de abandono familiar. Esto sucede cuando el Tribunal Supremo, a partir de su sentencia del 3 junio de 2014 (STS),

equipara el maltrato psicológico, que supuestamente deriva del hecho de haber sido abandonado el testador, con el maltrato de obra. En el caso enjuiciado, entiende que su desatención por parte de los legitimarios le provoca un menoscabo o lesión de su salud mental y que además tal conducta atenta contra su dignidad. (Esther Arroyo y Esther Farnós, 2015, p. 7) ${ }^{24}$

23 Publicado en el Diario Oficial de la Generalitat de Cataluña (DOGG) núm. 5175, del $17 / 07 / 2008$.

24 Concretamente, la susodicha STS, Sala la., núm. 258/2014, del 3 junio recoge, literalmente, lo siguiente: "En el presente caso, y conforme a la prueba practicada, debe puntualizarse que, fuera de un pretendido abandono emocional, como expresión de la libre ruptura de un vínculo afectivo o sentimental, los hijos, aquí recurrentes, incurrieron en un maltrato psíquico y reiterado contra su padre del todo incompatible con los deberes elementales de respeto y consideración que se derivan de la relación jurídica de filiación, con una conducta de menosprecio y de abandono familiar que quedó evidenciada en los últimos siete años de vida del causante en donde, ya enfermo, quedó bajo el amparo de su 
Esta nueva línea doctrinal se confirma con la STS del 30 de enero de 2015, la cual siguiendo el mismo iter argumentativo, supone la consolidación de una interpretación flexible del maltrato de obra, incluyendo el maltrato psicológico como justa causa de desheredación.

Como aprecia Hilario Mondragón (2018, pp. 17 y 18) citando a Represa Polo, de ello se puede entender que el maltrato psicológico es una modalidad del maltrato de obra y que a su vez el abandono familiar es una modalidad del maltrato psicológico. Por lo tanto, la desatención familiar podría, en principio, considerarse dentro del dinamismo conceptual del maltrato de obra, lo cual es verídico. De hecho, el Tribunal Supremo, en las relevantes sentencias comentadas de 2014 y 2015, no habilita directamente la falta de relación familiar o el abandono emocional como causa autónoma de desheredación.

En todo caso, el abandono, el ingreso en un centro asistencial o dejación y abandono en cualquier ubicación fuera del ámbito familiar, el desafecto y la desatención son causas de desheredación subsumibles en el artículo 853.2 del CGesp como un claro maltrato psíquico, en tanto constituyen causa directa de la angustia y sufrimiento para el ascendiente, que, en ocasiones, viene acompañado también de su vertiente física. (Berrocal, Ana Isabel, 2015, p. 942) $)^{25}$

Asimismo, cabe recordar que la doctrina del Tribunal Supremo, hasta tiempos muy recientes, no admitió que el abandono sentimental a los progenitores pudiese ubicarse dentro del maltrato de obra. Ello se debía a la rigidez que ha existido a la hora de interpretar las causas de desheredación. (Gómez-Cornejo, Lourdes, 2016, p.1615)

No obstante, a partir de 2011, ${ }^{26}$ Mondragón, Hilario (2018, p. 14) detecta una mutación de la doctrina del Tribunal Supremo hacia una interpretación extensiva y con posibilidad de analogía de las causas de desheredación. Este autor, citando a Carrau Carbonell, expone que la propia jurisprudencia más reciente dispone que no se pueden ni añadir ni quitar

hermana, sin que sus hijos se interesaran por él o tuvieran contacto alguno; situación que cambió, tras su muerte, a los solos efectos de demandar sus derechos hereditarios".

25 En otras palabras, Lourdes Gómez-Cornejo (2016, p. 1614) asevera que el incumplimiento de deber de cuidado y atención de los padres debe dar lugar a la posibilidad de desheredar, ya que, como sabemos, la legítima tiene como una de sus causas la solidaridad familiar.

26 Prueba de ello es la SAP de Málaga, Sec. 5a., núm. 130/2011, del 30 marzo. 
causas de privación de su derecho a un legitimario. En cambio, lo que sí se puede es hacer más extensivas las causales contempladas por los artículos 852 a 855 del CCesp.

Valiosa mención merece el legislador colombiano, quién finalmente - a diferencia de España - se ha atrevido a incorporar el abandono familiar como causa de indignidad sucesoral en el apartado 6 del artículo 1025 del CGco, en los siguientes términos: "El que abandonó sin justa causa a la persona de cuya sucesión se trata, estando obligado por ley a suministrarle alimentos. Para los efectos de este artículo, entiéndase por abandono: la falta absoluta o temporal a las personas que requieran de cuidado personal en su crianza, o que, conforme a la ley, demandan la obligación de proporcionar a su favor habitación, sustento o asistencia médica". Tal reforma ha entrado en vigor por medio de la Ley 1893 de 2018, del 24 de mayo, por medio de la cual se ha modificado el citado artículo.

Hay que aclarar que se excluye de los efectos de la norma el abandono que se origine en una justa causa o si, pese a haber ocurrido, el causante perdonó dicha situación. A mayor concreción, en Cataluña el perdón deberá ser concedido por el causante en escritura pública - tanto si la reconciliación o el perdón son anteriores o posteriores a la desheredación-, siendo los mismos irrevocables (CCGat, art. 451-1).

Vemos pues, comparando, que el derecho de sucesiones ha tendido a incorporar la causa de desheredación por ausencia de relación familiar. El germen de esta innovación lo encontramos en la nueva realidad social, constatándose un aumento de la esperanza de vida de la población, pero también, este envejecimiento está acompañado de un auge de enfermedades neurodegenerativas generadoras de escenarios de dependencia de los ancianos (a menudo no atendidos en el ámbito familiar). A ello, hay que añadir nuevas formas de modelos familiares, la incorporación de la mujer en la vida laboral, la movilidad laboral misma y, por qué no decirlo, un incremento del individualismo en las relaciones intrafamiliares que lleva aparejado un desamparo tanto material como afectivo de los ascendientes por parte de sus hijos. Todo ello, ha llevado a la ciencia jurídica a reinterpretar las causas de desheredación y adecuarlas al nuevo contexto. (Berrocal, Ana Isabel, 2015, p. 931)

Como se ha mostrado, después de examinar la desheredación de descendientes por ausencia de relación familiar, Luis Javier de Almansa (2012, p. 36) concluye de forma certera que

Esta obra está bajo una Licencia Creative Commons

Atribución-NoComercial-SinDerivar 4.0 Internacional, IIJ-UNAM.

Boletín Mexicano de Derecho Comparado, núm. 160, enero-abril de 2021, pp. 361-385. 
Códigos modernos y jurisprudencia reciente tienden a reducir los derechos de los legitimarios, ajustándose a la realidad de la sociedad contemporánea en la que prevalece el interés en procurarle una formación a los hijos, sobre el interés en garantizarles un valor patrimonial cuando falten los progenitores.

Finalmente, en cuanto a la libertad testamentaria, un aspecto esencial que, de paso, incidiría en la reforma del sistema legitimario, radicaría en la inclusión de las "causas abiertas para desheredar". Estas causas son aquellas que agrandan la libertad de testar admitiendo un elevado margen interpretativo. Sin embargo, vale la pena puntualizar, como exponen Galicia, Gorka y Castellanos, Sandra (2018, p. 33), que el aumento de dicha libertad no puede producirse a costa de una mayor inseguridad y de una judicialización de las relaciones familiares, como ocurriría de adoptarse un modelo marco a partir de cláusulas de desheredamiento flexibles y abiertas.

En resumen, resulta interesante la reflexión de las profesoras Esther Arroyo y Esther Farnós (2015, p. 22), las cuales al referirse a la cláusula de desheredación por abandono familiar observan que

la necesidad de incrementar la libertad de testar exige derogar la legítima y allanar el camino hacia su conversión en un derecho de alimentos. Cualquier intento de debilitarla mediante la actualización de las causas de desheredación genera más problemas que los que pretende solucionar.

\section{IV. ¿HAGIA UNA MAYOR LIBERTAD DE TESTAR?}

"La libertad de testar material puede considerarse como una manifestación de la dignidad de la persona y del libre desarrollo de la personalidad aplicado al derecho de sucesiones". (Paloma de Barrón, Paloma, 2016, p. 11)

Precisamente en el fenómeno sucesorio, Ángel María López y López (1994, p. 31) aprecia intereses en conflicto, entre los cuales: a) de orden individual patrimonial y b) de orden familiar. El primero, correspondiente al titular fallecido y a su facultad discrecional sobre el destino de sus bienes; el segundo, correspondiente a los intereses inherentes que ostentan, según este autor, los familiares del de cuius en relación con la distribución de su patrimonio. Es aquí donde apreciamos un conflicto de intereses, dimanando contradicciones fundamentales para mantener la coexistencia 
de dichos intereses de autonomía de libertad del causante y los intereses de solidaridad interfamiliar.

Como indica Ernest J. Weinrib (2017, pp. 256 y 257), el modo de como las formas de justicia son efectivizadas en los sistemas jurídicos se halla sujeto a las variaciones inherentes a su interpretación y aplicación públicas. Así, las formas de la justicia coexisten con indeterminaciones cuya resolución puede variar de época a época y de cultura a cultura. Por tanto, este teórico del derecho, desde la vertiente filosófica del "formalismo", asegura que entendiendo el derecho positivo como un orden coherente, este no puede ignorar la historia, la positividad y la realidad social del derecho.

Concretamente en materia sucesoria, no podemos olvidar que

las leyes que regulan las sucesiones por causa de muerte pueden y deben cambiar, sobre todo a la vista de los cambios que se están produciendo en la familia y en el derecho de familia, y también en las fortunas y en los modos de transmisión de la riqueza en la sociedad actual. (Paloma de Barrón, 2016, p. 11$)^{27}$

Carlos Lasarte (2015) razona que "la existencia de la legítima implica una restricción de la libertad de testar testamentaria, que se trata de una imposición establecida por el legislador al causante, en beneficio de las personas más cercanas o allegadas a él y que forman parte, en consecuencia, de su círculo familiar" (p. 163).

Precisamente en relación con la concepción de círculo familiar, trazando una línea hacia una mayor libertad para testar, Ángel María López y López (1994), a partir de un juicio de constitucionalidad, observa que nuestra sociedad considera que el "mínimo de familia" está formado alrededor de la pareja, sus descendientes y ascendientes, y tal vez los hermanos de ambos cónyuges o pareja. Con esta premisa, propone que

más allá de los descendientes y los ascendientes, y los propios cónyuges, nada impediría al legislador suprimir cualquier llamamiento forzoso, y con amplia posibilidad de configurar el quantum, la forma y el lugar del llamamiento; y también configurar un orden de llamamiento ab intestato que se extienda tan solo al primer grado de los colaterales. (p. 57)

27 Citando a otros autores de relieve como Fuentes Martínez, Delgado Echeverría, Magariños Fuentes.

Esta obra está bajo una Licencia Creative Commons

Atribución-NoComercial-SinDerivar 4.0 Internacional, IIJ-UNAM.

Boletín Mexicano de Derecho Comparado, núm. 160, enero-abril de 2021, pp. 361-385. 
Alejandro Platero (2017, p. 289) cita a autores como Aguilar Díaz, quien da argumentos a favor de la legítima, en cuanto a la justificación de su origen y finalidad, de suerte tal que

somos de la idea de que lo que el legislador quiso asegurar incorporando el sistema de legítima, es acertado si su fin es el de garantizar la continuidad de la familia respecto de quienes están en potestad del padre de familia, es decir, de quienes aún no están en condiciones de garantizar su independencia económica. (Aguilar, Richard, 2015, p. 79)

Es más, asevera Ramiro Rodríguez (2012, pp. 188 y 189) que hay autores que, con el propósito de proteger a los hijos, incluso han llegado a sostener que debería eliminarse la libertad de testar.

Alejandro Platero (2017, p. 317) admite que muchas voces de importancia manifiesta critican la permanencia en pleno siglo XXI de la legítima, aunque considera acertada esta figura y defiende su subsistencia por ser "su fin último el de garantizar la estabilidad de lo más importante de la vida de un ser humano, aunque a veces no se dé cuenta de ello, su familia"; argumento este, no compartido por lo endeble de su exposición y la concepción plenamente subjetiva que tiene este autor en cuanto a la importancia de la familia, sin que nadie pueda, a mi juicio, conocer ni imponer las prioridades vitales de otra persona.

Por el contrario, el autor Valverde y Valverde cita opiniones según las cuales debería, en todo caso, garantizarse al testador absoluta libertad para disponer de sus bienes después de su muerte, por cuanto que la voluntad individual claramente expresada encarnaba el ideal de justicia, reservándose la operancia de la ley únicamente para en caso de sucesión ab intestato. (Ramiro Rodríguez, 2012, pp. 188 y 189).

Los partidarios de esta posición, que contrasta de forma radical con la previsión legal actual, son proclives a remitirse al derecho angloamericano, "por ser el exponente de una libertad de testar irrestricta e ilimitada en la que los padres no tenían que hacer previsión ni provisión testamentarias en favor de sus hijos" (Aurelio Barrio, 2007, p. 2730). Sin embargo, Oughton, erigiéndose como la doctrina más autorizada en la materia, matiza que "la libertad de testar absoluta en sentido estricto solo se conoció en Inglaterra desde 1891 ("Mortmain \& Charitable Uses Act") hasta 1938 ("Inheritance [Family Provision] Act")" (Aurelio Barrio, 2007, p. 2736). 
Con todo, la realidad jurídica en Cataluña, España y Colombia - y por extensión a la práctica totalidad de sistemas jurídicos-, no es otra que la de conceder libertad para testar, aunque instituyendo las legítimas o asignaciones forzosas ${ }^{28}$ para garantizar a los parientes más cercanos al causante la herencia o, al menos, parte de ella.

En términos de aparente lógica jurídica, indica Ramírez Rodríguez (2012, p. 189) que en Colombia el testamento viene a ser una manifestación de voluntad libre y consciente de una persona, para que se produzcan determinadas consecuencias jurídicas después de su fallecimiento, derivado de la autonomía de la voluntad y con raíces en el derecho de propiedad y en la libertad de las personas. Ahora bien, ¿es suficiente la libertad para testar que rige en el derecho de sucesiones colombiano y, por extensión, en el español? ¿O se puede cuestionar por un excesivo constreñimiento del testador por vía de una legítima excesivamente larga, con el subterfugio del principio de solidaridad o protección familiar?

Si bien lo cierto es que hay doctrina dispar en la restricción a la libertad de testar que supone la legítima, siendo cuestión controvertida que ha ocasionado profundos debates y críticas, se converge en la posición de aquellos autores que están en total desacuerdo con la configuración actual de la legítima, considerando que

la actual regulación de la legítima del Código Civil no tiene cabida en una concepción de la persona y familia propias del siglo XXI, que nada tienen que ver con la que existía en el tiempo de la Codificación, por lo que, consideramos que la legítima debería desaparecer por completo, siendo desterrada de las leyes, dejando a salvo, eso sí, la protección de los menores e incapacitados, única justificación que encontramos hoy a la institución. (Ángel Acedo, 2014, p. 155) $)^{29}$

Esto es así, porque

28 En Colombia, las asignaciones forzosas previstas en el art. 1226 del CCcol, tras la reforma operada por la Ley 1934 de 2018, son: los alimentos que se deben por la ley a ciertas personas, la porción conyugal y las legítimas.

29 Además, para comprender la obsolescencia del sistema legitimario - en referencia al CCesp - , es de gran interés ver las consideraciones a nivel sociológico y estadístico que exhibe Aurelio Barrio (2007), constatando un amplio consenso doctrinal en cuanto a la necesidad de revisión del Código en esta materia. 
admitiendo que el fundamento de las legítimas se halla en el principio de solidaridad intergeneracional en el seno de la familia, la realización de este principio aboga por rechazar una legítima uniforme para una categoría de parientes, sean los descendientes o los ascendientes (Antoni Vaquer, 2007, p. 14).

Ahondando en la cuestión de concebir la legítima como figura protectora que operase en casos de "necesidad familiar" de los legitimarios, Antoni Vaquer (2007, pp. 4-10) expone, como solución intermedia, que los legitimarios tengan derecho a una cuota fija de los bienes de la herencia o de su valor, única y exclusivamente si se encuentran en tal circunstancia de menesterosidad, por la cual "la solidaridad intergeneracional esté llamada a jugar un papel efectivo. Así ocurre con los descendientes menores de edad y con quienes están afectados por discapacidades o son incapaces para el trabajo".

Sin embargo, el mismo Antoni Vaquer (2007, p. 15) prosigue señalando que este tipo de configuración conllevaría múltiples inconvenientes: determinar hasta cuándo cabría ejercer la pretensión a la legítima, sus mayores costes de transacción, una mayor litigiosidad familiar con múltiples pleitos, así como una complejidad a nivel probatorio; pues obligaría a las partes a proporcionar elementos de prueba suficientes de detalles íntimos de sus vidas, por lo general, escasamente documentados.

Además, en caso de aplicarse la legítima solamente en caso de necesidad, habría que apreciar una incongruencia que debilitaría el fin último de este cambio de paradigma. En este sentido, si concurriese un "supuesto de desheredación con causa justa con una situación de necesidad en el legitimario desheredado, esta circunstancia no activaría ningún tipo de mecanismo de solidaridad que condujera a emplear la herencia del causante para solucionar dicha situación de necesidad" (Paloma de Barrón, 2016, p. 15), por lo que quedarían consolidadas las causales de desheredamiento como preponderantes frente a la legítima. Con todo, el hecho que aquél que con su proceder haya merecido la desheredación, independientemente de su situación económica, quedase fuera de la herencia del causante, no sería una cuestión que generase gran controversia, puesto que se asumiría como una consecuencia plenamente lógica y defendible ética y jurídicamente.

En definitiva, con la institución del desheredamiento — más habiendo emergido la nueva causal por abandono familiar- 
incluso podría suceder que todos los legitimarios fueran susceptibles de ser desheredados conforme a la ley y no se dieran las circunstancias para que opere el derecho de representación. En este caso desaparecería la legítima, y el causante sería absolutamente libre para decidir el futuro de su entero patrimonio hereditario. (Paloma de Barrón, 2016, pp. 14 y 15).

A colación de cuanto expuesto, sea como sea, lo que se debe replantear es el concepto de "solidaridad intergeneracional". Hoy, vemos como la legítima sólo responde a razones de parentesco por consanguinidad o por afinidad. No obstante, como aprecia Paloma de Barrón (2016, p. 15), si se parte de que, "técnicamente, para poder ejercer la solidaridad es precisa una situación previa de necesidad, deberíamos concluir que este fundamento solo lo es en los casos en que se prevé un derecho de alimentos sucesorios". Esta autora fundamenta su crítica al sistema actual en detectar que la legítima se atribuye a los legitimarios sin reparar en sus necesidades económicas, transmitiéndose generalmente a la futura generación en un momento en que los perceptores ya detentan suficientes recursos para su subsistencia.

A mayor abundamiento, es constatable empíricamente que "en la mayoría de los casos, a la muerte del causante, sus ascendientes habrán fallecido o tendrán una edad muy avanzada, mientras que sus hijos estarán en una franja de edad comprendida entre los 40 y los 55 años" (Antoni Vaquer, 2007, p. 9). Al respecto, la mayoría de los doctrinantes que se han ocupado de esta materia han reiterado cuanto comentado por Valladares Rascón, señalando que "la herencia no tiene ya la función de transmitir de padres a hijos los medios de sustento de la familia, sino que suele ser un bienvenido complemento a la jubilación" (Aurelio Barrio, 2007, p. 2713).

Asimismo, Antoni Vaquer (2007, p. 8) cita a Magariños Blanco y Cobas Cobiella, quienes centran con dureza su crítica al sistema de legítima tildando su carácter de absurdamente obligatorio "ya que con independencia de la fortuna o ingresos familiares los padres están obligados a designarles en el testamento la legítima estricta por lo menos (...) que en muchos casos no lo merecen y en otros ni siquiera lo necesitan".

Llegados a este punto, sin intención de polemizar pero sí de llevar el debate y la reflexión hacia la más estricta radicalidad, Aurelio Barrio (2007, p. 2719), citando a Navarro Viñuales, enumera como posible hi- 
pótesis "la instauración de la libertad de testar. Esto es, un sistema puro de libre disposición mortis causa sin ningún género de restricción o cortapisa, ni tan siquiera suavizado por prestaciones de carácter asistencial en beneficio de los más próximos parientes del causante o de su cónyuge". Siendo pragmático, el contraste tan severo que supondría la libertad absoluta con la enraizada tradición en nuestro derecho sucesorio - tanto en Cataluña, España, como en Colombia - complica esta opción, por lo que difícilmente el atrevimiento del legislador llegará a tal extremo.

\section{CONCLusiones}

1. Pese a sopesar que la legislación colombiana y española todavía no deja suficiente autonomía de la voluntad al testador, todos los considerandos expuestos a lo largo de este estudio nos llevan a concluir que la libertad de testar está cobrando, cada día más, una inconmensurable fuerza y razón de ser.

2. Concretamente, se constata la tendencia en derecho sucesorio de admitir como causal de desheredamiento el abandono o ausencia de relación familiar con el causante. En este ámbito, he de destacar el papel pionero que ha jugado el derecho civil catalán, con la introducción de dicha causal en 2008 mediante la aprobación del libro cuarto de su Código Civil. Finalmente, aunque diez años más tarde, el legislador colombiano también ha tomado esta senda, a fin de preservar la coherencia de su derecho con la nueva realidad y contexto social.

Por el contrario, sorprende que en derecho común español todavía no se haya reformado el Código Civil en aras de incluir, explícitamente, esta causal de desheredamiento; si bien se viene aplicando, de facto, a partir de la envidiable y meritoria labor hermenéutica del Alto Tribunal desde su sentencia del 3 de junio de 2014, confirmada por la del 30 de enero de 2015.

3. Consiguientemente, de una forma u otra, en los tres ordenamientos jurídicos analizados ya opera esta nueva previsión legal de desheredamiento por abandono familiar, lo cual sugiere la actual predisposición en derecho de sucesiones de atenuar la "sagrada" institución de la legítima, siendo un síntoma más conducente hacia una mayor libertad para el futuro causante. 
Sin embargo, la libertad de testar no puede producirse a partir de un modelo de cláusulas de desheredamiento flexibles y abiertas, puesto que la inseguridad jurídica y la elevada judicialización son contraproducentes y supondrían un coste demasiado elevado. Por tanto, es más conveniente reformar el sistema sucesorio a partir de atemperar la legítima, regulando una legítima corta, que mantener una elevada cuota legitimaria pero ampliando las causas de desheredación.

4. No podemos seguir justificando la institución de la legítima con base en un principio de "solidaridad intergeneracional". Se concluye en tal sentido a partir de las siguientes premisas:

En primer lugar, porque actualmente se atribuye la legítima sin seguir ningún criterio que tome en consideración los legitimarios necesitados, si los hubiere. Asimismo, tampoco la desheredación tiene en cuenta si el desheredado está o no en situación de necesidad.

En segundo lugar, porqué en nuestros días la legítima se transfiere a la subsiguiente progenie en un momento intranscendente para sus necesidades de sustento, por estar el legitimario en una edad avanzada más pronta a la jubilación que en su etapa inicial de desarrollo personal autónomo.

A sabiendas de esta incongruencia sistémica, se vislumbran dos opciones:

Suprimir la legítima por la carencia de justificación alguna de la perdurabilidad de una institución, que sin justa causa lo que hace es limitar la libertad para testar, contraponiéndose a un principio básico en derecho privado como es el de la libre autonomía de la voluntad.

O bien reconfigurarla exclusivamente para situaciones de necesidad del legitimario, operando de forma extensiva el principio de solidaridad intergeneracional.

Imponer la segunda tesis nos llevaría, por ende, a la modificación no sólo del sistema legitimario, sino de otras figuras en derecho sucesorio como la del desheredamiento, imponiendo una barrera a los efectos de éste en los casos que se pruebe la situación de necesidad del legitimario desheredado.

A mayor abundamiento, se presentan dificultades para reformular la legítima en pro, única y exclusivamente, de aquellos legitimarios en situación de necesidad: como la propia inseguridad jurídica para el beneficiario de la legítima, la obligación de probar la situación de necesidad de éste y el aumento de la judicialización de las sucesiones mortis causa.

Esta obra está bajo una Licencia Creative Commons

Atribución-NoComercial-SinDerivar 4.0 Internacional, IIJ-UNAM.

Boletín Mexicano de Derecho Comparado, núm. 160, enero-abril de 2021, pp. 361-385. 
5. A colación de cuanto expuesto, parece tambalearse la propia institución de la legítima, lo cual, ciertamente no es cuestión baladí. Entonces, lo que difícilmente puede ser cuestionable es que la tendencia en este ámbito conduce inexorablemente a otorgar un mayor peso a la libertad testamentaria del causante. Consiguientemente, los ordenamientos jurídicos español y colombiano, al menos, deberían introducir reformas de cierto calado en el sentido de reducir las cuotas y aproximarse a la apuesta de legítima corta (un cuarto) vigente en derecho civil catalán.

\section{BIBLIOGRAFÍA}

Acedo Pencio, Ángel (2014). Derecho de sucesiones. El testamento y la herencia. Madrid. Dykinson.

Aguilar DÍAZ, Richard (2015). De la libertad para testar con la legítima. La Ley Derecho de Familia: Revista Jurídica sobre Familia y Menores (6), 75-84. ARroyo I AMAYUElaS, Esther y FARNÓs AMORÓs, Esther (2015). Entre el testador abandonado y el legitimario desheredado ¿A quién prefieren los tribunales? InDret (2), 1-32.

Barrio Gallardo, Aurelio (2007). Atemperar la rigidez de la legítima. Revista Doctrinal Aranzadi Civil-Mercantil (3), 2711-2738.

Berrocal Lanzarot, Ana Isabel (2015). El maltrato psicológico como justa causa de desheredación de hijos y descendientes. Revista Crítica de Derecho Inmobiliario (748), 928-952.

Cobas Cobiella, María Elena y Joz Latorre, Christian de (2017). La modernización del derecho de sucesiones. Algunas propuestas. Cuestiones de Interés furídico, IDIBE, 1-68.

Almansa MORENO-BARRERA, Luis Javier de (2012). ¿Debe introducirse en el derecho civil común la "falta de relación familiar" como causa para desheredar a hijos y otros descendientes? Aletheia: Cuadernos Críticos del Derecho (1), 27-37.

BARrón Arniches, Paloma de (2016). "Libertad de testar y desheredación en los derechos civiles españoles. InDret (4), 1-57.

DELGADO ECHEvERRÍA, Jesús (2006). Una propuesta de política del derecho en materia de sucesiones por causa de muerte. Derecho de sucesiones: presente y futuro: XI [i.e. XII] Fornadas de la Asociación de Profesores de Derecho 
Civil. Santander, 9 a 11 de febrero de 2006. Murcia. Universidad de Murcia, Servicio de Publicaciones, 13-172.

FERRER RIBA, Josep (2008). El nuevo derecho catalán de sucesiones. InDret.

Galicia AizPuruA, Gorka y Castellanos Cámara, Sandra (2018). Últimas reformas y propuestas de reforma en derecho de sucesiones. Revista Doctrinal Aranzadi Civil-Mercantil (3), 27-70.

Gómez-CORnejo Tejedor, Lourdes (2016). El cambio de sesgo en la jurisprudencia en torno a las causas de desheredación en el derecho común español. Revista Crítica de Derecho Inmobiliario (755), 1609-1629.

LAMARGA MARQUÈS, Albert (2009a). Relacions familiars i atribucions successòries legals. Novetats en la regulació de la llegítima i la quarta vidual. Quinzenes Fornades de Dret Català a Tossa. El nou dret successori del Codi Civil de Catalunya. http://civil.udg.es/tossa/2008/textos/pon/index.htm [consultado el 2 de septiembre de 2019].

LAMARCA MARQUÈS, Albert (2009b). El Llibre IV del Codi Civil de Catalunya. Actualitat Parlamentària (16), 54-73.

Lasarte Álvarez, Carlos (2015). Principios de derecho civil VII, Derecho de sucesiones (10a. ed.). Marcial Pons.

LóPEZ y LÓPEZ, Ángel María (1994). La garantía institucional de la herencia. Derecho Privado y Constitución (3), 29-62.

Mondragón Martín, Hilario (2018). Ampliación de las causas de desheredación de hijos y descendientes. Vlex (167), 8-33.

Platero Alcón, Alejandro (2017). Las injustas diferencias existentes en la libertad de testar dentro del territorio español. Vniversitas (135), 283324.

Puig SALELLAS, Josep Maria (1984). Notes sobre una eventual reforma de la llegítima. Materials de les III Jornades de Dret Català a Tossa. La reforma de la Compilació: el sistema successori. Tossa de Mar. Càtedra de Dret Civil Català Duran i Bas.

RodríGUez LóPEZ, Ramiro (2012). Las sucesiones en el siglo XXI: nuevas tendencias doctrinales y jurisprudenciales. Bogotá. Universidad La Gran Colombia.

VAQUER AlOY, Antoni (2007). Reflexiones sobre una eventual reforma de la legítima. InDret (3), 1-25.

Weinrib, ERnest J. (2017). La idea de derecho privado. Madrid. Marcial Pons.

Esta obra está bajo una Licencia Creative Commons

Atribución-NoComercial-SinDerivar 4.0 Internacional, IIJ-UNAM.

Boletín Mexicano de Derecho Comparado, núm. 160, enero-abril de 2021, pp. 361-385. 


\section{Furisprudencia}

España. Tribunal Supremo. (2015). Sentencia 59/2015, del 30 enero. España. Tribunal Supremo. (2014). Sentencia 258/2014, del 3 junio.

España. Audiencia Provincial de Málaga. (2011). Sentencia 130/2011, de 30 marzo.

\section{Legislación}

Colombia. "Código Civil". Ley 57 de 1887. http://bit.ly/3c6xOrT

Colombia. Ley 1893 de 2018, del 24 de mayo, por medio de la cual se modifica el artículo 1025 del Código Civil. http://bit.ly/3pgb4cX

Colombia. Ley 1934 de 2018, del 2 de agosto, por medio de la cual se reforma y adiciona el Código Civil. http://bit.ly/3s TpVMy

España. "Código Civil". Real Decreto del 24 de julio de 1889 por el que se publica el Código Civil. http://bit.ly/21dWGFW

España, Cataluña. "Código Civil de Cataluña”. Ley 10/2008, del 10 de julio, del libro cuarto del Código Civil de Cataluña, relativo a las sucesiones. http://bit.ly/39dzttS 
Esta revista forma parte del acervo de la Biblioteca Jurídica Virtual del Instituto de Investigaciones Jurídicas de la UNAM
httos://biblio juridicas unam $\mathrm{mx} /$ biv DOI: http://dx.doi.org/10.22201/iij.24484873e.2021.160.15980

Universidad Nacional Autónoma de México, IIJ-BJV, 2021 